\title{
Oxytocin Infusion Reduces Repetitive Behaviors in Adults with Autistic and Asperger's Disorders
}

\author{
Eric Hollander*,', Sherie Novotny', Margaret Hanratty', Rona Yaffe', Concetta M DeCaria', \\ Bonnie R Aronowitz' and Serge Mosovich' \\ 'Department of Psychiatry, Seaver Autism Research Center, Mount Sinai School of Medicine, New York, USA
}

\begin{abstract}
Autism is a neurodevelopmental disorder characterized by dysfunction in three core behavioral domains: repetitive behaviors, social deficits, and language abnormalities. There is evidence that abnormalities exist in peptide systems, particularly the oxytocin system, in autism spectrum patients. Furthermore, oxytocin and the closely related peptide vasopressin are known to play a role in social and repetitive behaviors. This study examined the impact of oxytocin on repetitive behaviors in 15 adults with autism or Asperger's disorder via randomized double-blind oxytocin and placebo challenges. The primary outcome measure was an instrument rating six repetitive behaviors: need to know, repeating, ordering, need to tell/ask, self-injury, and touching. Patients with autism spectrum disorders showed a significant reduction in repetitive behaviors following oxytocin infusion in comparison to placebo infusion. Repetitive behavior in autism spectrum disorders may be related to abnormalities in the oxytocin system, and may be partially ameliorated by synthetic oxytocin infusion.
\end{abstract}

Neuropsychopharmacology (2003) 28, 193-198. doi: I 0. I038/sj.npp. I 30002 I

Keywords: autism; Asperger's disorder; oxytocin; peptide; obsessive-compulsive behaviors

\section{INTRODUCTION}

Autism is a neurodevelopmental disorder characterized by dysfunction in three core behavioral dimensions: repetitive behaviors, social deficits, and language abnormalities. Of specific interest here, the repetitive behavior domain involves compulsive behaviors, unusual attachments to objects, rigid adherence to routines or rituals, and repetitive motor mannerisms such as stereotypies and self-stimulatory behaviors. The social deficit dimension involves deficits in reciprocal social interactions, lack of eye contact, diminished ability to carry on conversation, and impaired daily interaction skills. It has been suggested that the neurohypophyseal peptides oxytocin and vasopressin may potentially contribute to the development of the repetitive behaviors found in autism spectrum disorder patients, as well as their social deficits (Insel et al, 1999). This theory is strengthened by evidence that suggests that abnormalities in the neural pathways for either oxytocin or vasopressin could account for many aspects of autism including the repetitive behaviors, early onset, cognitive deficits, alterations in neural development, predominance in boys, and

*Correspondence: Dr E Hollander, Department of Psychiatry, Box 1230, Mount Sinai School of Medicine, One Gustave L Levy Place, New York, NY 10029, USA. Tel: +212 241 3623, Fax: +212987 4031, E-mail: eric.hollander@mssm.edu

Received 19 February 2002; revised 19 June 2002; accepted 24 June 2002 genetic loading (Insel et al, 1999; Witt et al, 1992; Modahl et al, 1998; Insel and Winslow, 1998; Insel and Young, 2001).

While oxytocin has a long established role in milk ejection and uterine contraction during labor, recent research suggests that oxytocin and the closely related peptide vasopressin play an important role in the development of normal cognition and, in particular, social behavior (Carter et al, 1992; Popik et al, 1992b; Insel and Hulihan, 1995; Witt et al, 1992). The nine amino acid peptides, oxytocin and vasopressin, are relayed from the human brain into the bloodstream via the posterior pituitary. These peptides are developmentally regulated, act both centrally and peripherally, and have been implicated in learning and memory in both rats and primates. Receptors for both peptides are located throughout the forebrain and brainstem. Oxytocin receptors, in particular, are extremely plastic, showing robust increases in response to gonadal steroids (Johnson et al, 1990), and significant variation throughout development (Shapiro and Insel, 1989).

The similarity of these peptides in closely related species has led researchers to investigate the role of oxytocin and vasopressin in animals. Studies have shown that social learning appears to be extremely dependent on these neuropeptides. Vasopressin has been found to be important in the formation of social memory, while oxytocin appears to be important in the retention of these newly formed memories (Popik et al, 1992a; Popik and Van Ree, 1992). Furthermore, oxytocin becomes crucial for learning associating factors such as olfactory cues (Nelson and Panksepp, 
1996; Ferguson et al, 2000). Oxytocin, when administered into the central nervous system by intracerebroventricular (ICV) minipump, increases the duration of physical contact in the absence of sexual interactions in male rats (Witt et al, 1992). Most relevant to the study of autism is the finding that both peptides are involved in the development of social attachments. Oxytocin was found to facilitate the development of partner preference in the absence of mating in female prairie voles, while administration of an oxytocin antagonist prevented partner preference but failed to interfere with mating (Insel and Hulihan, 1995). For males, vasopressin has been shown to evoke partner preference and aggression after mating (Winslow et al, 1993). Recently, it has been found that children with autism show alterations in the endocrine oxytocin system, suggesting that deficits in oxytocin peptide processing may be important in the development of autism (Green et al, 2001).

Genetic studies have examined social and other behaviors relevant to autism in rodents with mutations of the peptide genes (Nishimori et al, 1996; Young et al, 1997). While oxytocin knockout mice (mice lacking the gene for oxytocin) exhibit normal mating, parturition, and maternal behavior, these animals fail to eject milk and the separation distress calls in knockout pups are significantly decreased relative to pups with oxytocin (Young et al, 1997). The latter finding may suggest that animals deficient in oxytocin are not distressed by the separation caused by the absence of social attachment. The knockout mice also reportedly showed deficits in other behaviors such as decreased social investigation and increased aggression (Insel et al, 1999). Recently, Ferguson et al (2000) found that mice lacking the oxytocin gene showed a failure to develop social memory, which was rescued by intraventricular administration of oxytocin, but not vasopressin.

Human studies provide further support for the theory that autism may be linked to oxytocin dysfunction. Modahl et al (1998) found that children with autism manifest lower plasma oxytocin levels than those of normal children. Unlike normal children, who show an increase in oxytocin plasma levels throughout development, children with autism fail to show a developmental increase in blood oxytocin levels. In normal children, Modahl et al found that the oxytocin plasma level was related to the mastery of social conventions and socialization items, while the opposite was found to be true in children with autism. Green et al (2001) reported deficits in oxytocin-processing peptides in autistic children. Of interest, genetic syndromes such as Prader-Willi (15q 13-14) have oxytocin abnormalities and a polypeptide that shares this chromosomal site influences pro-hormone convertace (PC2), whose gene (20p 11-1-11-2) is proximal to the oxytocin gene, and chromosomal abnormalities at this site have been identified in autistic individuals (Cook, 1998).

In addition to the social domain, evidence suggests a relationship between oxytocin and repetitive behaviors. In animal studies, oxytocin-administered ICV has been shown to induce stereotypic behaviors such as stretching, repetitive grooming, startle, and squeaking in mice (Drago et al, 1986; Insel and Winslow, 1991; Meisenberg and Simmons, 1983a; Nelson and Alberts, 1997), grooming, particularly of the genital regions, in rats (Drago et al, 1986; van Wimersma Greidanus et al, 1990), and wing-flapping in chicks (Panksepp, 1992). Peripheral and central oxytocin administration also inhibits extinction and this promotes perseverative behaviors (de Wied et al, 1993). Central administration of vasopressin results in increased aggression and self-directed behaviors in rodents (Brown and King, 1984; Winslow and Insel, 1991), which Insel et al (1999) has suggested may be related to the self-injurious behavior, often stereotyped, observed in children with autism. Although analogies between animal and human behavior must be viewed with caution, these studies suggest that oxytocin may play a role in repetitive behaviors, a core feature of autism.

Elevated oxytocin levels have been found in patients with non-tic-related obsessive-compulsive disorder (OCD) (Leckman et al, 1994), in children and adolescents with OCD (Swedo et al, 1992) and in Prader-Willi syndrome (Martin et al, 1998), a disorder with a high risk for comorbid OCD. One recent study was unable to confirm these results (Altemus et al, 1999); however unlike the Leckman study, this study did not separate patients with tics, or a family history of tics from those without tics. It might be hypothesized that a deficit in central oxytocin receptor function might result in a compensatory increase in oxytocin levels. Swedo et al (1992) found that oxytocin levels increased in children and adolescents with OCD who responded to treatment with clomipramine, suggesting that increasing oxytocin levels might be associated with a reduction in severity of repetitive behaviors. However, intranasal oxytocin has been used to treat patients with OCD in a number of small studies with mixed results (Ansseau et al, 1987; Den Boer and Westenberg, 1992; Salzberg and Swedo, 1992; Epperson et al, 1996). Only Ansseau et al (1987) found any benefit from intranasal oxytocin, and that one patient developed serious side effects including psychosis and memory impairment.

We have previously reported on the repetitive behavior domain in autism, and linked the severity of these core symptoms to one aspect of serotonin function (5HT1d sensitivity) (Hollander et al, 2000) and one specific B cell immune marker (D8/17) (Hollander et al, 1999). In this study, it was hypothesized that infusion of synthetic oxytocin might modulate the severity of this repetitive behavior domain in patients with autism spectrum disorders. Since we did not have a measure of social attachment that might be sensitive to change over a brief period of time (over $4 \mathrm{~h}$ ), this domain was not assessed in this study.

\section{METHODS AND MATERIALS}

To evaluate the role of oxytocin in autism spectrum disorders, 15 adult patients (mean age $=32.9$ years, range $=19.4-55.6) \quad(14$ males, 1 female $)$ diagnosed with autism $(N=6)$ or Asperger's disorder $(N=9)$ received oxytocin and placebo challenges during visits separated by 2-3 weeks to our General Clinical Research Center. All patients were carefully evaluated and diagnosed according to both DSM-IV criteria and the Autism Diagnostic Interview-Revised (Lord et al, 1994), on which the patients with autism scored within the autistic range and those with Asperger's disorder did not. Patients and their guardians 
signed written informed consent, and the study was carried out in accordance with the Declaration of Helsinki as adopted and promulgated by the National Institutes of Health. All patients were medically healthy, without a current or past history of schizophrenia, psychotic disorders, substance abuse, other Axis I mental disorders, or seizure disorders. Patients were of average intelligence, with a mean IQ $( \pm S D)$ of $90.33( \pm 9.90)$ (range $=74-110)$. Nine patients were medication free for greater than 1 year prior to the study; three patients were medication free for greater than 6 weeks prior to the study (one was previously on fluoxetine, one on sertraline, and one on bupropion); and the remaining three patients were medication free for a minimum of 2 weeks prior to and throughout the study (one was previously on fluvoxamine and risperidone, one on sertraline, and one on clonazepam).

Each subject served as their own control; a control group of individuals who were normal or from another diagnostic category was not included because the repetitive behaviors being monitored are characteristic of autism spectrum patients but are not exhibited by either normal adults or adults in other diagnostic categories. Since we would not predict a change in these behaviors with the administration of oxytocin, it was more meaningful to use the patients on placebo as their own controls. They underwent two identical challenge days in which they received a continuous infusion over $4 \mathrm{~h}$ of synthetic oxytocin (pitocin) or placebo. All subjects were admitted into the General Clinical Research Center on the evening prior to each challenge. Following an overnight fast, the subject was awakened at 8:00 am and an indwelling intravenous catheter inserted. At 8:30 am vital signs were taken, and these continued to be monitored every half hour. At 9:00 am, $6 \mathrm{cc}^{3}$ of blood was drawn and the oxytocin/placebo infusion was administered in a randomized double-blind fashion. The initial vial of pitocin $(10 \mathrm{u} / \mathrm{ml})$ combined aseptically with a $1.01 \mathrm{bag}$ of normal saline was first given at a rate of $10 \mathrm{ml} / \mathrm{h}$. The infusion was initiated at a low rate to minimize potential side effects, and the rate gradually titrated up. Specifically, the infusion rate was titrated every $15 \mathrm{~min}$ by $25 \mathrm{ml}$ in the first hour, $50 \mathrm{ml}$ in the second hour, $100 \mathrm{ml}$ in the third hour, and held constant at the maximum rate of $700 \mathrm{ml} / \mathrm{h}$ during the fourth hour. The combined solution, rotated in an infusion bottle to ensure thorough mixing, was added to the system by a constant infusion pump to control accurately the rate of infusion. Staff members were given specific instructions to discontinue increasing the rate of infusion if the patient experienced significant side effects. In order to assess possible cardiovascular effects, blood pressure and pulse were recorded every half hour. Oral temperature was recorded at every hour. All 15 subjects returned in 2-3 weeks for an identical challenge administered with the other infusion substance.

Severity of repetitive autistic behaviors was evaluated using a method developed during past research with this population. Six behaviors were assessed: need to know, repeating, ordering, need to tell/ask, self-injury, and touching. The ratings were completed at baseline (0), 60, 120,180 , and $240 \mathrm{~min}$ and reported the frequency of each of the six repetitive behaviors using a four-point ordinal scale with the following values: $0=$ never, $1=$ rarely, $2=$ sometimes, $3=$ constantly. These ratings were done following a 15-20 min interview during which several other measures were administered and the rater had the opportunity to observe the patient's behavior in this domain. We obtained an estimate of the scale's validity during another autism study in which 15 ratings were conducted by three raters using both this instrument and the YBOCS compulsion severity scale, utilizing the YBOCS symptom checklist to elicit types of repetitive behaviors. We found that this scale had a correlation of 0.81 with the YBOCS compulsion scale $(p=0.01)$. We obtained $100 \%$ agreement between raters on the measure of repetitive behaviors when rating a patient over the same time period.

A repeated measure analysis of variance (ANOVA) was conducted looking at the two infusions (oxytocin vs placebo) over time $(0,60,120,180$, and $240 \mathrm{~min})$. A logarithmic transformation was done for the repetitive behavior ratings because the data were not normally distributed. Baseline differences on the oxytocin vs placebo days were examined using paired sample $t$-tests. Differences in response between patients with autism and patients with Asperger's disorder were examined using independent sample $t$-tests. Pearson correlations between behavioral response and physiological measures (blood pressure, pulse, and oral temperature) and $\chi^{2}$ analysis comparing behavioral responses in patients with and without side effects were also conducted. A significance criterion of $p<0.05$ was used in all analyses.

\section{RESULTS}

There was no significant or trend difference in baseline severity of repetitive behaviors on the oxytocin and placebo days. There was a significantly greater reduction in repetitive behaviors over time following oxytocin compared to placebo (drug $\times$ time interaction: $\mathrm{F}=3.487, \mathrm{df}=4,52$, $p=0.027$ ); see Figure 1. There was no significant main effect for drug $(\mathrm{F}=1.835, \mathrm{df}=1,13, p=0.199)$, but there was a

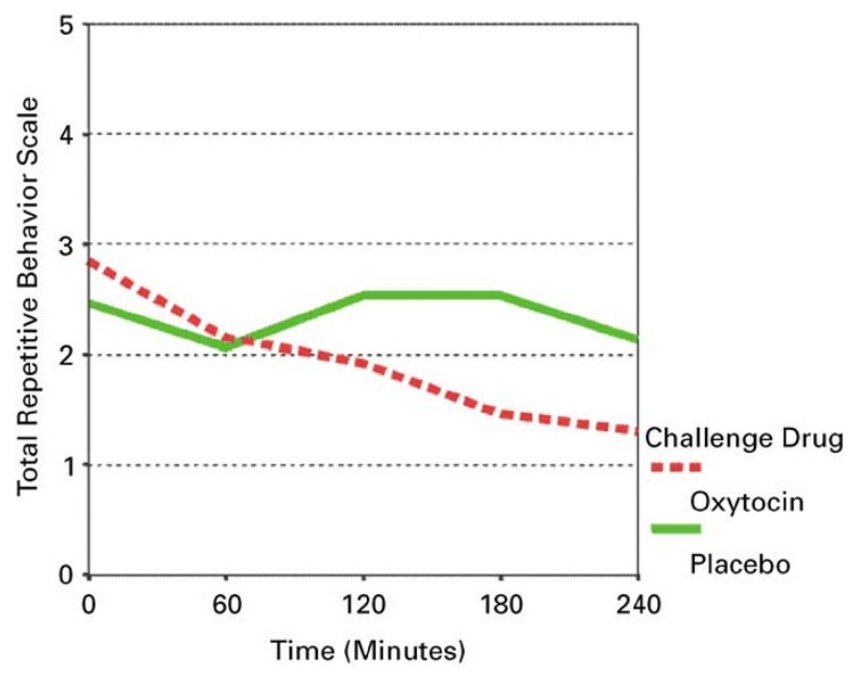

Figure I Effects of oxytocin vs placebo infusion on repetitive behaviors in autism spectrum disorder patients over time. Mean scores were significantly lower over time following oxytocin vs placebo $(F=3.487$, $\mathrm{df}=4,52, p=0.027)$ 


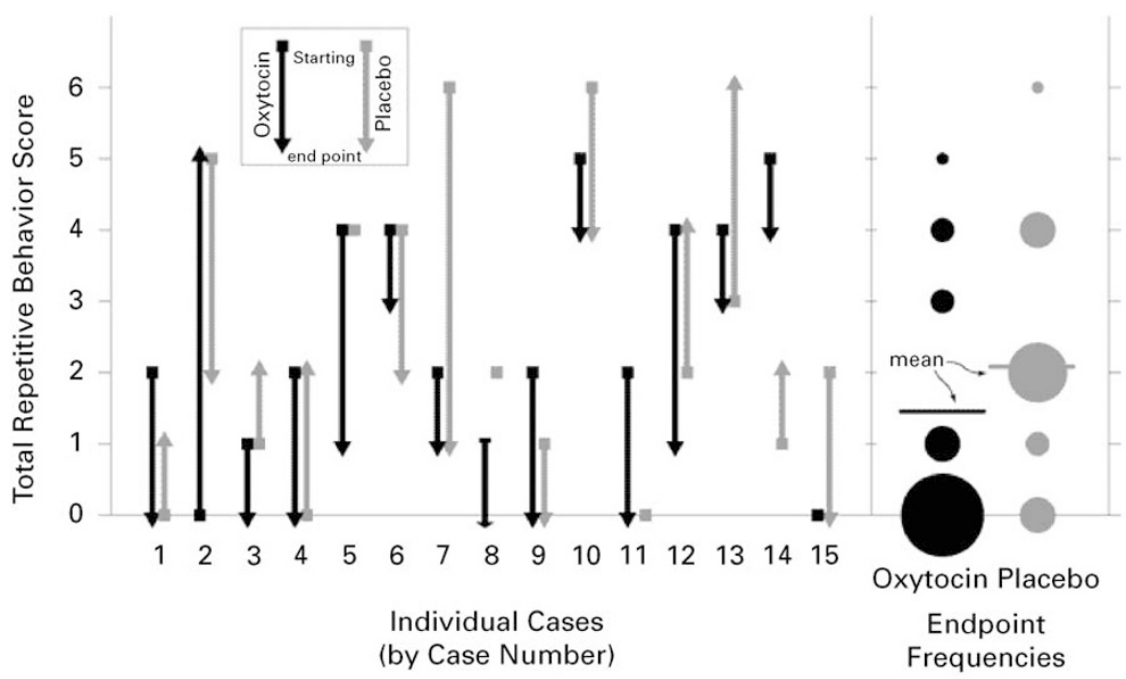

Figure 2 Effects of oxytocin and placebo infusion on repetitive behaviors from baseline ( 0 min, indicated by square) to end point ( 240 min, indicated by arrow) for each individual autism spectrum disorder patient. Mean and frequency distribution at end point for oxytocin vs placebo, larger circles indicate greater frequency.

significant main effect for time $(\mathrm{F}=3.239, \mathrm{df}=4,52$, $p=0.030$ ). For the purpose of understanding possible differences between the individual dimensions of repetitive behavior, we conducted analyses of the individual items using the same ANOVA design as used for the primary analysis. There were no significant differences at $p<0.05$ for the individual dimensions on the oxytocin $v s$ placebo infusions over time, but two items showed a directional difference $(p<0.10)$; these were repeating (time $\times$ drug interaction: $\mathrm{F}=2.70, \mathrm{df}=4,52, p=0.086)$ and touching behavior (time $\times$ drug interaction: $\mathrm{F}=2.444, \mathrm{df}=4,52$, $p=0.093$ ).

The baseline (0) and endpoint (240 $\mathrm{min})$ ratings for each individual patient are presented in Figure 2, showing that on the oxytocin infusion there was a decrease in repetitive behaviors for 13 patients (86.7\%), an increase for one patient and no change for another patient, in contrast to ratings taken during the placebo infusion when only six patients (40\%) showed decreased repetitive behaviors, while another six increased, and two were unchanged.

Individuals who responded to oxytocin often had a decrease in the number of different types of repetitive behavior from three or four at baseline to none or one at end point. Thus, not only did the severity decrease over time, but did the number of different types of repetitive behaviors on oxytocin, which was clinically meaningful. In contrast, during the placebo challenge, six of the participants had an increase in repetitive behaviors while only one did on oxytocin, which suggests that the structured challenge situation itself may have caused an increase in these behaviors in some patients, which was prevented by oxytocin. Patients with autism did not differ from patients with Asperger's disorder following oxytocin infusion $(t=0.687, \mathrm{df}=13, p=0.504)$.

There were no significant effects of either infusion on blood pressure, pulse, or temperature, and these measures did not marginally or significantly correlate with the behavioral measures of response to the infusion agents. Side effects on oxytocin were mild and included drowsiness, anxiety, depression, headache, tingling, backache, trembling, restlessness, stomach cramps, and enuresis. Placebo side effects included mild drowsiness, anxiety, and headache. There was no relationship between the presence or number of side effects and behavioral response to oxytocin or placebo.

\section{DISCUSSION}

As hypothesized, administration of exogenous oxytocin decreased the core autistic repetitive behaviors measured; on oxytocin not only did the severity of the behaviors decrease over time, but so did the number of different types of repetitive behaviors. To our knowledge, this is the first study to examine the effect of oxytocin infusion on core behaviors in autism. The data suggest that oxytocin may play a role in the severity of common compulsive/repetitive behaviors in autism spectrum disorders. Thus, the results suggest that dysfunction of the oxytocin system might contribute to characteristics of autistic disorder beyond those of the social dimension, strengthening the theory that oxytocin dysfunction plays a role in the etiology of autism.

Further studies are needed to investigate possible mechanisms by which exogenous oxytocin infusion leads to behavioral changes such as those demonstrated in this study. Early studies seemed to indicate that oxytocin and vasopressin, or at least physiologically significant amounts of these peptides, are excluded access to most regions of the CNS by the blood-brain barrier (BBB) (Ermisch et al, 1988; Meisenberg and Simmons, 1983b). However, more recently, a bidirectional saturable active transport mechanism across the BBB has been demonstrated for vasopressin (Banks et al, 1987; Zlokovic et al, 1990). The behavioral effects of peripherally circulating peptides may be indirect such as via the alteration of the $\mathrm{BBB}$ permeability to other substances. Oxytocin and vasopressin have been shown to affect the $\mathrm{BBB}$ permeability to $3 \mathrm{H}$-orotic acid and an RNA precursor 
in some brain regions (Landgraf et al, 1977, 1978). Specific binding sites on capillary endothelial cells have been demonstrated for both peptides (Ermisch and Landgraf, 1990, Ermisch et al, 1988, 1993; Kretzchmar et al, 1986), possibly affecting BBB permeability. In addition, and of more importance, the peptide may be binding to receptors in peripheral tissues, and since these targets feed back to the CNS, this may result in the observed changes in behavior.

Another possible mechanism by which peripherally administered oxytocin and vasopressin may affect the CNS is through the formation of active fragments that may cross the BBB. Fragments of both oxytocin and vasopressin have been shown to cross the $\mathrm{BBB}$ and affect memory processes (de Wied et al, 1972, 1987; de Wied, 1976; de Wied and Versteeg, 1979; Walter et al, 1975; Burbach et al, 1983a,b; Tanabe et al, 1997; Rainbow et al, 1979). One promising strategy for peptide delivery to the brain is through chemical modification resulting in a peptide or fragment with favorable BBB permeability, which has important implications for the development of clinically relevant treatments.

The findings of the present study must be viewed with caution, given the small number of patients studied, only one of whom was female. Since the study was restricted to adults, no conclusion regarding oxytocin can be made about childhood autism spectrum disorders. Future studies, with larger sample sizes, are needed to replicate these findings; further investigations into the relationship between exogenous oxytocin and the $\mathrm{BBB}$ are needed to understand the mechanism by which exogenous oxytocin may exert behavioral effects such as those demonstrated in this study. Other sensitive outcome measures capable of measuring change in other core dimensions over relatively brief periods of time (especially social and communication deficits) need to be developed, and these social and communication deficit domains should be tested in further studies of oxytocin. Social behaviors were not sampled. It is true that we would expect social behaviors to be sensitive to oxytocin; however, it was not possible to provide an environment in which we could conduct a biological challenge that also provided a reasonable environment in which to sample typical social behaviors. Of interest, studies in OCD suggest that increased oxytocin levels are associated with greater repetitive behaviors, whereas in autism oxytocin administration is associated with a decrease in repetitive behaviors, suggesting differences between these disorders. Future studies should include contrast groups such as OCD patients to determine the specificity of the findings. Other pharmacological approaches in autism that target brain oxytocin levels or receptors (eg OTR and V1A) and that have long-term central effects are needed, but currently are limited by a lack of available agents with these potential therapeutic properties. Gene therapy strategies that may alter oxytocin receptor expression in specific brain regions may eventually hold promise (Young et al, 1997). Despite the limitations of this study, the findings are potentially clinically relevant in helping to evaluate the contribution of oxytocin to one specific behavioral domain (repetitive behaviors) in autism spectrum disorder patients, and complement prior studies that link this behavioral domain to specific alterations in 5HT (Hollander et al, 2000) and immune (Hollander et al, 1999) function.

\section{ACKNOWLEDGEMENTS}

Supported in part by grants from the Seaver Foundation, National Alliance for Research on Schizophrenia and Depression, Cure Autism Now, National Alliance for Autism Research and Grant 5 MO1 RR00071 for the Mount Sinai General Clinical Research Center from the National Center for Research Resources, National Institutes of Health.

\section{REFERENCES}

Altemus M, Jacobson KR, Debellis M, Kling M, Pigott T, Murphy DL et al (1999). Normal CSF oxytocin and NPY levels in OCD. Biol. Psychiatry 45: 931-933.

Ansseau M, Legros JJ, Mormont C, Cerfontain JL, Papart P, Greenen V et al (1987). Intranasal oxytocin in obsessivecompulsive disorder. Psychoneuroendocrinology 12: 231-236.

Banks WA, Kastin AJ, Horvath A, Michals EA (1987). Carriermediated transport of vasopressin across the blood-brain barrier of the mouse. J Neurosci Res 18: 326-332.

Brown R, King MG (1984). Arginine vasotocin and aggression in rats. Peptides 5: 1135-1138.

Burbach JPH, Bohus B, Kovacs GL, Van Nispen JW, Grven HM, de Wied D (1983a). Oxytocin is a precursor of potent behaviourally active neuropeptide. Eur J Pharmacol 94: 125-131.

Burbach JPH, Kovacs GL, de Wied D, Van Nispen JW, Greven HM (1983b). A major metabolite of arginine-vasopressin in the brain is a highly potent neuropeptide. Science 221: 1310-1312.

Carter CS, Williams JR, Witt DM, Insel TR (1992). Oxytocin and social bonding. Ann NY Acad Sci 652: 204-211.

Cook EHJ (1998). Genetics of autism. Mental Retardation Dev Disabil Res Rev 4: 113-120.

Den Boer JA, Westenberg HGM (1992). Oxytocin in obsessive compulsive disorder. Peptides 13: 1083-1085.

de Wied D (1976). Behavioral effects of intraventricularly administered vasopressin and vasopressin fragments. Life Sci 19: 685-690.

de Wied D, Diamant M, Fodor M (1993). Central nervous system effects of the neurohypophyseal hormones and related peptides. Front Neuroendocrinol 14: 251-302.

de Wied D, Gaffori O, Burbach JPH, Kavacs GL, van Ree JM (1987). Structure activity relationship studies with c-terminal fragments of vasopressin and oxytocin on avoidance behaviors of rats. $J$ Pharmacol Exp Ther 241: 268-274.

de Wied D, Greven HM, Lande S, Witter A (1972). Dissociation of the behavioral and endocrine effects of lysine vasopressin by tryptic digestion. Br J Pharmacol 45: 118-122.

de Wied D, Versteeg DH (1979). Neurohypophyseal principles and memory. Fed Proc 38: 2348-2454.

Drago F, Pedersen CA, Caldwell JD, Prange Jr AJ (1986). Oxytocin potently enhances novelty-induced grooming behavior in the rat. Brain Res 368: 287-295.

Epperson CN, McDougle CJ, Price LH (1996). Intranasal oxytocin in obsessive-compulsive disorder. Biol Psychiatry 40: 547-549.

Ermisch A, Landgraf R (1990). Vasopressin-blood-brain barrier - brain performance. Circulating Regulatory Factors and Neuroendocrine Function. Plenum Press: New York, pp 71-89.

Ermisch A, Landgraf R, Brust P, Kretzschmar R, Hess J (1988). Peptide receptors of the cerebral capillary endothelium and the transport of amino acids across the blood-brain barrier. In: Rakic L, Begley DJ, Davson H, Zlokovic BV (eds). Peptide and Amino Acid Transport Mechanisms in the Central Nervous System. Stockton Press: New York, pp 41-53.

Ermisch A, Brust P, Kretzchmar R, Ruhle H-J (1993). Peptides and the blood-brain barrier. Physiol Rev 73: 489-527. 
Ferguson JN, Young LJ, Hearn EF, Matzuk MM, Insel TR, Winslow JT (2000). Social amnesia in mice lacking the oxytocin gene. Nat Genet 25: 284-288.

Green LA, Fein D, Modahl C, Feinstein C, Waterhouse L, Morris M (2001). Oxytocin and autistic disorder: alteration in peptide forms. Biol Psychiatry 50: 609-613.

Hollander E, DelGiudice-Asch G, Simon L, Schmeidler J, Cartwright C, DeCaria CM et al (1999). B lymphocyte antigen D8/17 and repetitive behaviors in autism. Am J Psychiatry 156: 317320.

Hollander E, Novotny S, Allen A, Aronowitz B, Cartwright C, DeCaria C (2000). The relationship between repetitive behaviors and growth hormone response to sumatriptan challenge in adult autistic disorder. Neuropsychopharmacology 22: 163-167.

Insel TR, Hulihan TJ (1995). A gender-specific mechanism for pair bonding: oxytocin and partner preference formation in monogamous voles. Behav Neurosci 109: 782-789.

Insel TR, O'Brien DJ, Leckman JF (1999). Oxytocin, vasopressin, and autism: is there a connection. Biol. Psychiatry 45: 145-157.

Insel TR, Winslow JT (1991). Central administration of oxytocin modulates the infant rat's response to social isolation. Eur $J$ Pharmacol. 203: 149-152.

Insel TR, Winslow JT (1998). Serotonin and neuropeptides in affiliative behaviors. Biol Psychiatry 443: 207-219.

Insel TR, Young LJ (2001). The neurobiology of attachment. Nature Reviews Neuroscience 2: 129-136.

Johnson AE, Coirini H, Insel TR, McEwen BS (1990). The regulation of oxytocin receptor binding in the ventromedial hypothalamic nucleus by testosterone and its metabolites. Endocrinology 128: 891-896.

Kretzchmar R, Landgraf R, Gjedde A, Ermisch A (1986). Vasopressin binds to microvessels from rat hippocampus. Brain Res 380: 325-330.

Landgraf R, Hess J, Hartmann E (1977). Effect of oxytocin on regional $3 \mathrm{H}$-orotic acid uptake in rat brain. Endokrinologie 70: $45-52$.

Landgraf R, Hess J, Ermisch A (1978). The influence of vasopressin on the regional uptake of $[3 \mathrm{H}]$ orotic acid by the rat brain. Acta Biol Med Ger 37: 655-658.

Leckman JF, Goodman WK, North WG, Chappell PB, Price LH, Pauls DL et al (1994). Elevated cerebrospinal fluid levels of oxytocin in obsessive-compulsive disorder Comparison with Tourette's syndrome and healthy controls. Arch Gen Psychiatry 51: 782-792.

Lord C, Rutter M, LeCouteur A (1994). Autism Diagnostic Interview-Revised: a revised version of a diagnostic scale for caregivers of individuals with possible pervasive developmental disorders. J Autism Develop Disorders 24: 659-685.

Martin A, State M, Anderson GM, Kaye WM, Hanchett JM, McConaha CW et al (1998). Cerebrospinal fluid levels of oxytocin in Prader-Willi syndrome: a preliminary report. Biol Psychiatry 44: 1349-1352.

Meisenberg G, Simmons WH (1983a). Centrally mediated effects of neurohypophyseal hormones. Neurosci Biobehav Rev 7: 263-280.

Meisenberg G, Simmons WH (1983b). Peptides and the bloodbrain barrier. Life Sci 32: 2611-2623.

Modahl C, Green L, Fein D, Morris M, Waterhouse L, Feinstein C, Levin H (1998). Plasma oxytocin levels in autistic children. Biol Psychiatry 43: 270-277.

Nelson E, Alberts JR (1997). Oxytocin-induced paw sucking in infant rats. Ann NY Acad Sci 807: 543-545.
Nelson E, Panksepp J (1996). Oxytocin mediates acquisition of maternally associated odor preferences in preweanling rat pups. Behav Neurosci 110: 583-592.

Nishimori K, Young LJ, Guo Q, Wang Z, Insel TR, Matzuk MM (1996). Oxytocin is required for nursing but is not essential for parturition or reproductive behavior. Proc Nat Acad Sci USA 93: 11699-11704.

Panksepp J (1992). Oxytocin effects on emotional processes: separation distress, social bonding, and relationships to psychiatric disorders. In: Pedersen C, Caldwell J, Jirikowski G, Insel $\mathrm{T}$ (eds). Oxytocin in Maternal Sexual and Social Processes. Vol, 652. New York Academy of Sciences, New York, 243-252.

Popik P, Van Ree JM (1992). Long term facilitation of social recognition in rats by vasopressin related peptides: a structureactivity study. Life Sci 50: 567-572.

Popik P, Vetulani J, van Ree JM (1992a). Low doses of oxytocin facilitate social recognition in rats. Psychopharmacology 106: 7174.

Popik P, Vos P, van Ree J (1992b). Neurohypophyseal hormone receptors in the septum are implicated in social recognition in the rat. Behav Pharmacol 3: 351-358.

Rainbow TC, Flexner JB, Flexner LB, Hoffman PL, Walter R (1979). Distribution, survival and biological effects in mice of a behaviorally active, enzymatically stable peptide: pharmacokinetics of cyclo-(Leu-Gly) and puromycin-induced amnesia. Pharmacol Biochem Behav 10: 787-793.

Salzberg AD, Swedo SE (1992). Oxytocin and vasopressin in obsessive-compulsive disorder. Am J Psychiatry 149: 713-714.

Shapiro LE, Insel TR (1989). Ontogeny of oxytocin receptors in rat forebrain: a quantitative study. Synapse 4: 259-266.

Swedo SE, Leonard HL, Kruesi MJ, Rettew DC, Listwak SJ, Berrettini W et al (1992). Cerebrospinal fluid neurochemistry in children and adolescents with obsessive-compulsive disorder. Arch Gen Psychiatry 49: 29-36.

Tanabe S, Shishido Y, Furushiro M, Kado K, Hashimoto S, Yokokura T, Ohsawa T (1997). Facilitation of passive avoidance response by newly synthesized cationized arginine vasopressin fragment 4-9 in rats. Pharmacol Biochem Behav 57: 251-256.

van Wimersma Greidanus TB, Kroodsma JM, Pot MLH, Stevens M, Maigret C (1990). Neurohypophyseal hormones and excessive grooming behavior. Eur J Pharmacol 187: 1-8.

Walter R, Hoffman PL, Flexner JB, Flexner LB (1975). Proc Nat Acad Sci USA 72: 4180-4184.

Winslow DM, Insel TR (1991). Social status in the pairs of male squirrel monkeys determines the behavioral response to central oxytocin administration. J Neurosci 11: 2032-2038.

Winslow JT, Hastings N, Carter CS, Harbaugh CR, Insel TR (1993). A role for central vasopressin in pair bonding in monogamous prairie voles. Nature 365: 545-548.

Witt DM, Winslow JT, Insel TR (1992). Enhanced social interactions in rats following chronic, centrally infused oxytocin. Pharmacol, Biochem Behav 43: 855-861.

Young LJ, Winslow JT, Wang Z, Gingrich B, Guo Q, Matzuk MM et al (1997). Gene targeting approaches to neuroendocrinology: oxytocin, maternal behavior, and affiliation. Hormones Behav 31: 221-231.

Zlokovic BV, Hyman S, McComb JG, Lipovac MN, Tang G, Davson $\mathrm{H}$ (1990). Kinetics of arginine-vasopressin uptake at the bloodbrain barrier. Biochim Biophys Acta 1025: 191-198. 